\title{
Effects of Condensate in the Exhalation Limb of Neonatal Circuits on Airway Pressure During Bubble CPAP
}

\author{
Tiffany M Youngquist, C Peter Richardson PhD, and Robert M DiBlasi RRT NPS FAARC
}

\begin{abstract}
BACKGROUND: Bubble CPAP is frequently used in spontaneously breathing infants with lung disease. Often bubble CPAP systems lack pressure alarms and pressure-release valves. We observed a large volume of condensate in the exhalation limb of a patient circuit and conducted a series of experiments to test the hypothesis that accumulated condensate could affect delivered pressures. METHODS: An anatomically accurate nasal airway model of a preterm infant was attached to a spontaneously breathing lung model. A bubble CPAP system was attached to the nasal airway with bi-nasal short prongs, and the rate of fluid condensation was measured. Next, tracheal pressures were monitored digitally to detect changes in airway pressure related to condensate accumulation. Measurements were obtained with volumes of $0,5,10,15$, and $20 \mathrm{~mL}$ of water in the exhalation limb, at flows of $4,6,8$, and $10 \mathrm{~L} / \mathrm{min}$. Measurements with $20 \mathrm{~mL}$ in the exhalation limb were recorded with and without a pressure-relief valve in the circuit. RESULTS: The rate of condensate accumulation was $3.8 \mathrm{~mL} / \mathrm{h}$. At volumes of $\geq 10 \mathrm{~mL}$, noticeable alterations in the airway pressure waveforms and significant increases in mean tracheal pressure were observed. The pressure-relief valve effectively attenuated peak tracheal pressure, but only decreased mean pressure by 0.5 $1.5 \mathrm{~cm} \mathrm{H}_{2} \mathrm{O}$. CONCLUSIONS: Condensate in the exhalation limb of the patient circuit during bubble CPAP can significantly increase pressure delivered to the patient. The back and forth movement of this fluid causes oscillations in airway pressure that are much greater than the oscillations created by gas bubbling out the exhalation tube into the water bath. We recommend continuously monitoring pressure at the nasal airway interface, placing an adjustable pressurerelief valve in the circuit, set to $5 \mathrm{~cm} \mathrm{H}_{2} \mathrm{O}$ above the desired mean pressure, and emptying fluid from the exhalation limb every 2-3 hours. Key words: bubble CPAP; condensate; resistance; patient safety; airway pressure; neonatal intensive care; maintenance; lung protection; noninvasive ventilation. [Respir Care 2013;58(11):1840-1846. (C) 2013 Daedalus Enterprises]
\end{abstract}

\section{Introduction}

Nasal bubble CPAP is a form of noninvasive respiratory support used in spontaneously breathing infants with lung

\footnotetext{
The authors are affiliated with the Center for Developmental Therapeutics, Seattle Children's Research Institute, Seattle, Washington. Dr Richardson is also affiliated with the Pulmonary Division, Department of Pediatrics, University of Washington School of Medicine, Seattle, Washington. Mr DiBlasi is also affiliated with the Respiratory Therapy Department, Seattle Children's Hospital, Seattle, Washington.
}

The authors have disclosed no conflicts of interest.

Ms Youngquist presented a version of this paper at the OPEN FORUM at the AARC Congress 2012, held November 10-13, 2012, in New Orleans, Louisiana. disease. Its popularity in the neonatal ICU has been on the rise since a multicenter randomized controlled trial ${ }^{1}$ showed no difference in the rate of complications between infants supported by bubble CPAP or ventilator-derived CPAP, as well as a lower incidence of reintubation in the bubble CPAP group. Clinicians prescribe the level of airway pressure desired for the infant and frequently use the depth of the expiratory tube in water (the water pressure seal) as an estimate of the pressure delivered to the patient.

Correspondence: Tiffany M Youngquist. E-mail: tiffymy1@u.washington. edu.

DOI: $10.4187 /$ respcare. 02322 
When applying bubble CPAP to infants, many institutions construct their own homemade systems. Unlike ventilator-derived CPAP, the homemade systems described in the literature frequently lack safety alarms and high-pressure pressure-relief valves. ${ }^{2-7}$

\section{See the Related Editorial on Page 1990}

Kahn et $\mathrm{al}^{8,9}$ have shown that the bias flow coursing through the circuit can lead to an underestimation of the delivered pressure. The present investigation pursues an additional clinical event that may also contribute to the disparity between tube depth setting and the actual pressure delivered to the patient. The aim of this study was to test the hypothesis that increases in the condensate level within the expiratory tubing would result in a greater pressure than a dry circuit.

\section{Methods}

\section{Lung Model}

We modeled lung mechanics using a neonatal test lung (ASL 5000, Ingmar Medical, Pittsburgh, Pennsylvania), configured to represent the pulmonary mechanics of an extremely-low-birth-weight infant with respiratory distress syndrome: lung compliance $0.5 \mathrm{~mL} / \mathrm{cm} \mathrm{H}_{2} \mathrm{O}$, resistance $100 \mathrm{~cm} \mathrm{H}_{2} \mathrm{O} / \mathrm{L} / \mathrm{s}$. The lung model was made to breathe spontaneously by setting a simulated pleural pressure profile: $10 \mathrm{~cm} \mathrm{H}_{2} \mathrm{O}$ (yielding tidal volume of $\sim 5 \mathrm{~mL}$ ), and breathing frequency 50 breaths $/ \mathrm{min} .{ }^{10}$

\section{Nasal Airway Model}

A head computed tomography scan from a 26-week gestational age infant was loaded into cranial imaging software (V-Works 4.0, CyberMed, Centreville, Virginia), upper airway anatomy was cropped out of each image, and relevant files were exported in a stereolithography format. Files were then loaded into a rapid prototyping system and a 3-dimensional model of the upper airway was printed with a 3-dimensional printer (V-Flash, 3D Systems, Rock Hill, South Carolina). The model was then glued to a $15 \mathrm{~mm}$ adapter to attach to the lung model.

\section{Bubble CPAP System}

All testing was conducted using a commercially available bubble CPAP system (Fisher \& Paykel, Auckland, New Zealand). A standard oxygen flow rotameter provided fresh gas to the dry side of the humidifier via the pressure manifold.

\section{QUICK LOOK}

\section{Current knowledge}

Nasal bubble CPAP is a form of noninvasive respiratory support used in spontaneously breathing infants with lung disease, and is often delivered with homemade devices that have not been safety tested and have few if any alarms.

\section{What this paper contributes to our knowledge}

During bubble CPAP, condensate in the expiratory limb of the ventilatory circuit significantly increased the delivered airway pressure and the magnitude of the pressure oscillations. Proximal airway pressure monitoring, a pressure-relief valve, and frequent removal of condensate from the circuit may improve safety during bubble CPAP.

\section{Instrumentation}

Micro-machined piezoresistive silicon pressure transducers (G4-V, All Sensors, Morgan Hill, California, range $0-100 \mathrm{~cm} \mathrm{H}_{2} \mathrm{O}$ ), for measuring airway pressure, were calibrated using 2-point calibrations with a pre-calibrated manometer (PM-23, Digitron, Devon, United Kingdom). Analog signals from the pressure transducer were sampled at $1,024 \mathrm{kHz}$ with a 16-bit analog-to-digital converter (DT BNC Box USB 9804, Data Translation, Waltham, Massachusetts) and recorded on a laptop computer. Pressure signals were recorded digitally and calculations of mean airway pressure, amplitude of oscillations in airway pressure, and peak frequency of oscillations were made using custom software (Visual Basic, Microsoft, Redmond, Washington).

\section{Rate of Condensate Accumulation}

The average rate of condensate accumulation in the exhalation limb during bubble CPAP was determined so that approximate volumes could be used in a controlled fashion for the second phase of testing. The nasal airway model was attached to the spontaneously breathing lung model. The expiratory circuit was removed from the bubble CPAP system and the mass of the dry circuit was measured on a scale $(n=3)$ and reattached to the bubble CPAP system. The expiratory hose was placed into a $27 \mathrm{~cm}$ fixed "Ushaped" configuration, ${ }^{11}$ and the position was secured by taping the hose to the table (Fig. 1). The CPAP level was set at $5 \mathrm{~cm} \mathrm{H}_{2} \mathrm{O}$, with a flow of $6 \mathrm{~L} / \mathrm{min}$. The nasal prongs were attached to the nasal airway openings and secured by a bonnet fixation. Continuous bubbling during the entire 


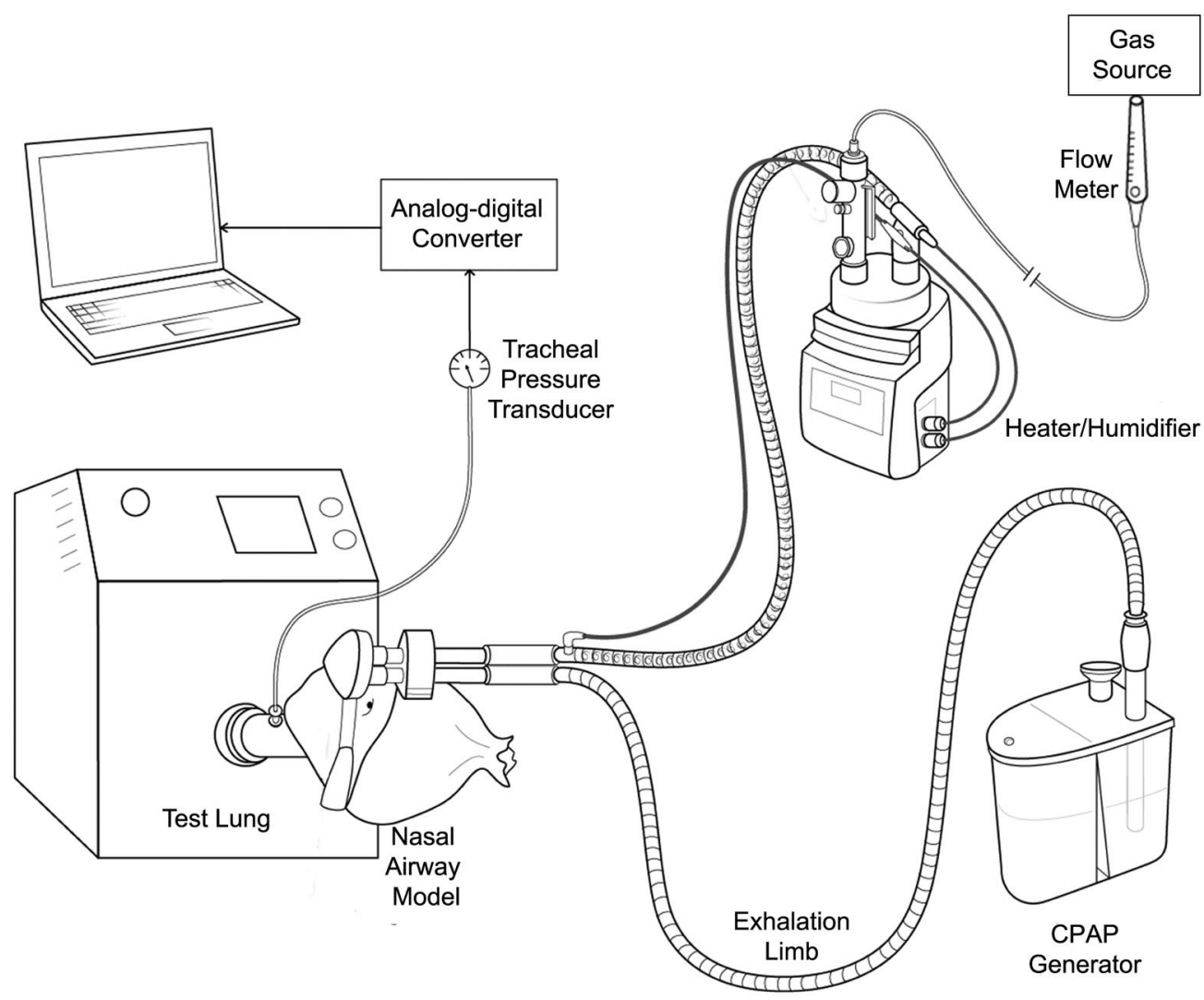

Fig. 1. Experimental setup.

respiratory cycle indicated a good seal at the prongs. The humidifier was set at $37^{\circ} \mathrm{C}$ in the Invasive Mode, and the internal components of the lung model were held at $37^{\circ} \mathrm{C}$ using an integrated warmer. Ambient temperature was controlled in the room $\left(\sim 21^{\circ} \mathrm{C}\right)$ with a pre-set thermostat, and an oscillating fan set on "medium" was placed $2.4 \mathrm{~m}$ away from the bubble CPAP system, to simulate drafts from ceiling vents or excessive movement around the circuit, which are encountered in the clinical setting.

The study began following a 20 -min temperature stabilization period with the system running. Every 2 hours the volume of accumulated fluid in the expiratory hose was assessed by removing and weighing the tubing and comparing the measurement to the mass of the dry circuit. Tubing was reattached to the bubble CPAP system after each measurement, without removing fluid. The lung model breathed for a total of 8 hours during bubble CPAP, and the experiment was conducted 3 times with a new dry circuit.

\section{Effect of Condensate on Delivered Pressure}

Nasal prongs were inserted into a nasal airway model and a tight seal (no leak) was made by forming medical- grade putty around the interface. The nasal airway model was connected to the test lung, and tracheal pressure $\left(\mathrm{P}_{\text {tracheal }}\right)$ was monitored between the nasal airway model and test lung in a simulated trachea consisting of small plastic 15-mm outer diameter adapters (see Fig. 1).

The initial measurements were recorded using a dry circuit, with no pressure manifold in the system, and $\mathrm{P}_{\text {tracheal }}$ was collected for 8 seconds, at flows of $4,6,8$, and $10 \mathrm{~L} /$ min. The expiratory hose was disconnected and water was added in $5 \mathrm{~mL}$ increments to the " $\mathrm{U}$ " in the exhalation circuit, though a feeding catheter attached to a glass syringe. $\mathrm{P}_{\text {tracheal }}$ measurements were obtained for 8 seconds at each flow setting, with volumes of 5, 10, 15, and $20 \mathrm{~mL}$ of water in the circuit. Three separate pressure measurements were recorded for each set of conditions.

\section{Effectiveness of the Pressure-Relief Valve}

Following the final measurement $(20 \mathrm{~mL}$ water), the bubble CPAP pressure manifold (pressure-relief valve) was introduced into the circuit. $\mathrm{P}_{\text {tracheal }}$ measurements were obtained for 8 seconds at each flow $(4,6,8$, and $10 \mathrm{~L} / \mathrm{min})$ with CPAP set to $5 \mathrm{~cm} \mathrm{H}_{2} \mathrm{O}$. 


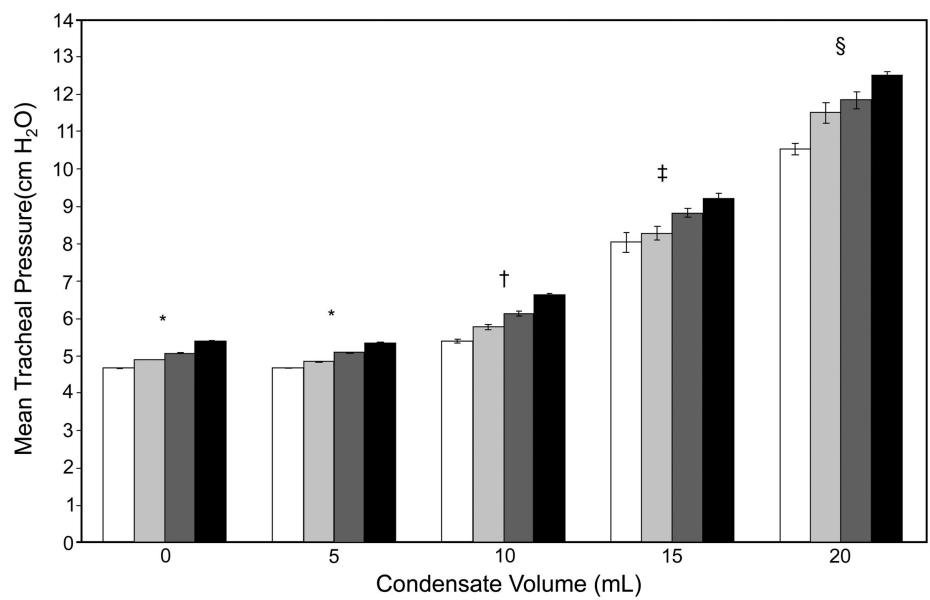

Fig. 2. Mean tracheal pressure with varying volumes of condensate in the exhalation limb. Groups not sharing similar symbols are significantly different $(P<.05)$.

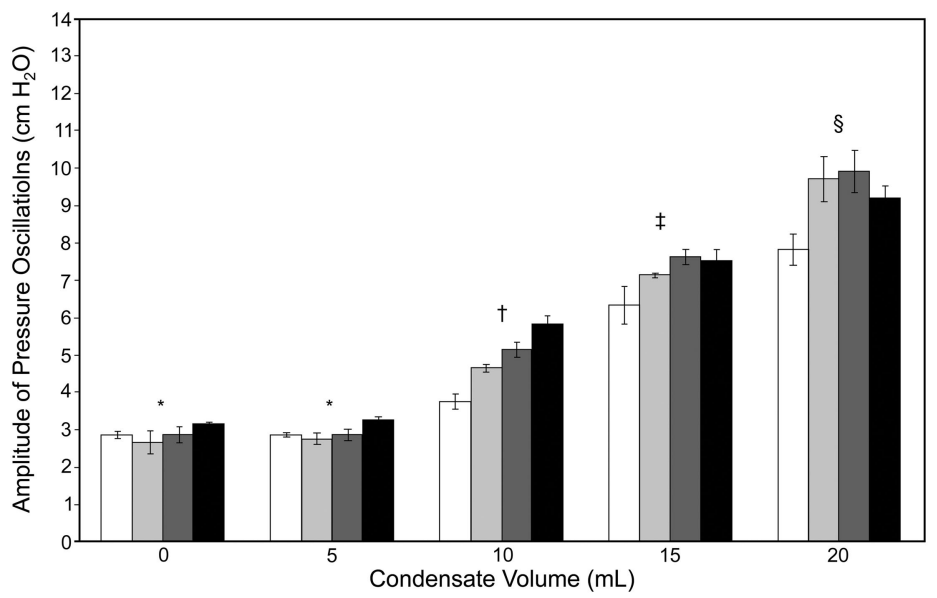

Fig. 3. Amplitude of oscillations in tracheal pressure with varying volumes of condensate in the exhalation limb. Groups not sharing similar symbols are different $(P<.05)$.

\section{Data Analysis}

Data from the study that assessed the rate of condensate accumulation were saved in a spreadsheet (Excel, Microsoft, Redmond, Washington), and the rate was calculated from a linear regression using the least-squares method.

Mean $\mathrm{P}_{\text {tracheal }}$ was calculated for each 8-second run $(n=3)$. The mean $\pm \mathrm{SD}$ of the amplitudes of the $\mathrm{P}_{\text {tracheal }}$ oscillations $\left(\Delta \mathrm{P}_{\text {tracheal }}\right)$ was then calculated from the $\mathrm{P}_{\text {tracheal }}$ signals using an algorithm (described elsewhere ${ }^{12}$ ) that determines the amplitude of individual oscillations. The peak frequency was calculated using spectral power analysis to define frequencies, with the maximum power observed in each testing condition.

For data collected without the pressure-relief valve in the system, a one-way analysis of variance was used, with a Tukey test for post hoc analysis, to compare the mean $\mathrm{P}_{\text {tracheal }}$ and $\Delta \mathrm{P}_{\text {tracheal }}$ at each volume of condensate at similar flows. Data collected with $20 \mathrm{~mL}$ of condensate in the circuit while the pressure-relief valve was in place were compared to data collected with the same volume of condensate in a circuit without a pressure-relief valve using a paired $t$ test. Statistical significance was set a priori at $P<.05$.

\section{Results}

The rate of fluid accumulation in the exhalation limb of the bubble CPAP system remained constant $\left(\mathrm{R}^{2}=0.99\right)$ at $3.8 \mathrm{~mL} / \mathrm{h}$ over the 8 -hour period. The condensate formed a pool in the low point of the expiratory circuit, which became intermittent at large volumes $(15$ and $20 \mathrm{~mL})$ as the air pushed past the occlusion. 

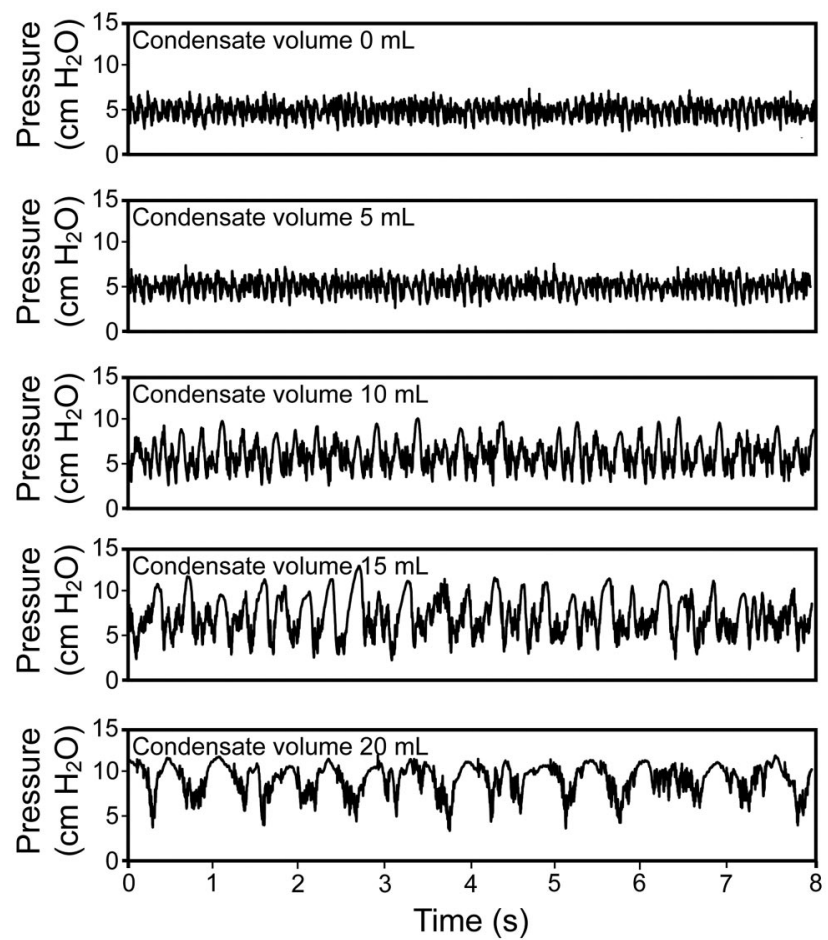

Fig. 4. Tracheal pressure waveforms with condensate volumes of $0,5,10,15$, and $20 \mathrm{~mL}$ at a CPAP depth setting of $5 \mathrm{~cm} \mathrm{H}_{2} \mathrm{O}$ and a flow of $8 \mathrm{~L} / \mathrm{min}$. The tracheal pressure signals were sampled at $1,024 \mathrm{kHz}$ for $8 \mathrm{~s}$.

There were no differences in the mean $\mathrm{P}_{\text {tracheal }}$ (Fig. 2) or $\Delta \mathrm{P}_{\text {tracheal }}$ (Fig. 3) between 0 and $5 \mathrm{~mL}$ at similar flows during bubble CPAP. However, the addition of larger volumes of fluid $(>5 \mathrm{~mL})$ to the exhalation limb increased both sets of pressure measurements at each flow $(P<.05)$.

Figure 4 shows examples of $P_{\text {tracheal }}$ waveforms. There were noticeable changes in pressure waveform characteristics at volumes $>5 \mathrm{~mL}$. The mean $\mathrm{P}_{\text {tracheal }}$ was $5.01 \pm$ $0.01 \mathrm{~cm} \mathrm{H}_{2} \mathrm{O}, 5.09 \pm 0.01 \mathrm{~cm} \mathrm{H}_{2} \mathrm{O}, 6.14 \pm 0.06 \mathrm{~cm} \mathrm{H}_{2} \mathrm{O}$, $8.84 \pm 0.01 \mathrm{~cm} \mathrm{H}_{2} \mathrm{O}$, and $11.85 \pm 0.22 \mathrm{~cm} \mathrm{H}_{2} \mathrm{O}$ with volumes of $0,5,10,15,20 \mathrm{~mL}$, respectively. The $\Delta \mathrm{P}_{\text {tracheal }}$ was $2.60 \pm 0.28 \mathrm{~cm} \mathrm{H}_{2} \mathrm{O}, 2.08 \pm 0.15 \mathrm{~cm} \mathrm{H}_{2} \mathrm{O}$, $5.01 \pm 0.20 \mathrm{~cm} \mathrm{H}_{2} \mathrm{O}, 7.60 \pm 0.21 \mathrm{~cm} \mathrm{H}_{2} \mathrm{O}$, and $9.90 \pm 0.57 \mathrm{~cm} \mathrm{H}_{2} \mathrm{O}$ with volumes of $0,5,10,15,20 \mathrm{~mL}$, respectively. The peak frequencies were $10.29 \pm 0.32 \mathrm{~Hz}$, $10.50 \pm 0.32 \mathrm{~Hz}, 4.17 \pm 0.07 \mathrm{~Hz}, 3.37 \pm 0.21 \mathrm{~Hz}$, and $1.67 \pm 0.70 \mathrm{~Hz}$ with volumes of $0,5,10,15,20 \mathrm{~mL}$, respectively.

The pressure-relief valve significantly decreased the mean $\mathrm{P}_{\text {tracheal }}$ and $\Delta \mathrm{P}_{\text {tracheal }}$ (Figs. 5 and 6, respectively, $P<.05)$, with each flow, with the exception of mean $\mathrm{P}_{\text {tracheal }}$ at $8 \mathrm{~L} / \mathrm{min}$. This component had a greater influence on $\Delta \mathrm{P}_{\text {tracheal }}$ than on mean $\mathrm{P}_{\text {tracheal }}$. Figure 7 compares 2 pressure waveforms with and without the pressurerelief valve. The frequency of $\Delta \mathrm{P}_{\text {tracheal }}$ was higher without the pressure-relief valve, and peak $\mathrm{P}_{\text {tracheal }}$ was well above

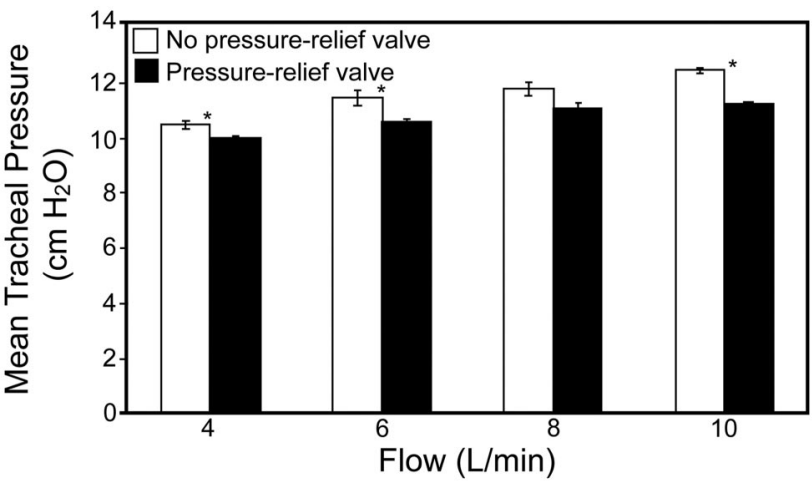

Fig. 5. Mean tracheal pressure with and without a pressure-relief valve in the circuit, with $20 \mathrm{~mL}$ of condensate in the circuit, and a CPAP depth setting of $5 \mathrm{~cm} \mathrm{H}_{2} \mathrm{O}$. ${ }^{*} P<.05$.

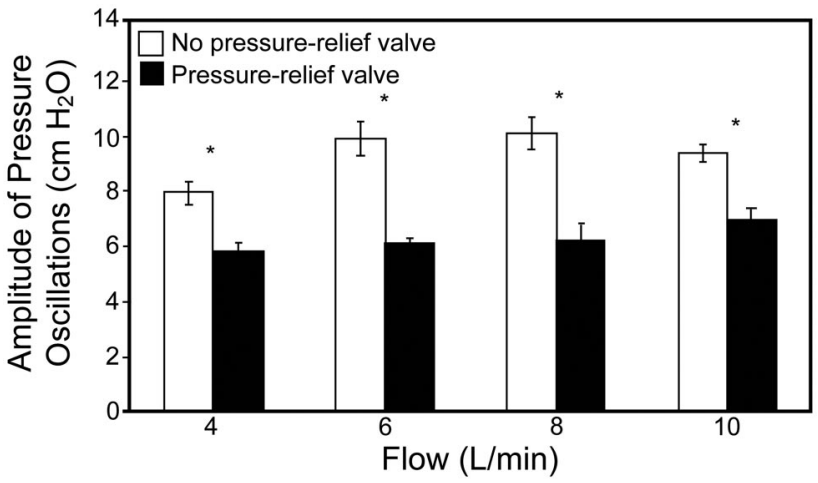

Fig. 6. Amplitude of tracheal pressure oscillations with and without a pressure-relief valve, with $20 \mathrm{~mL}$ of condensate in the circuit, and a CPAP depth setting of $5 \mathrm{~cm} \mathrm{H}_{2} \mathrm{O}$. ${ }^{*} P<.05$.

$17 \mathrm{~cm} \mathrm{H}_{2} \mathrm{O}$. However, with the pressure-relief valve the peak $\mathrm{P}_{\text {tracheal }}$ was blunted to $13-14 \mathrm{~cm} \mathrm{H}_{2} \mathrm{O}$, and the consequent lower frequency resulted in a longer duration at the peak $\Delta \mathrm{P}_{\text {tracheal }}$, which in turn resulted in only minor decreases in the mean $P_{\text {tracheal }}$.

\section{Discussion}

The major finding of this study was that condensate in the exhalation limb of the patient circuit during bubble CPAP can result in mean $\mathrm{P}_{\text {tracheal }}$ significantly higher than the CPAP depth setting. Additionally, the flow-induced movement of accumulated condensate and the patient's spontaneous respiratory efforts cause $\mathrm{P}_{\text {tracheal }}$ oscillations that are greater than the oscillations created solely by gas bubbling out of the expiratory tubing. The combination of increases in both mean $\mathrm{P}_{\text {tracheal }}$ and $\Delta \mathrm{P}_{\text {tracheal }}$ results in airway pressures that may surpass safe levels.

To discuss this point in detail, at volumes of $10 \mathrm{~mL}$, mean $\mathrm{P}_{\text {tracheal }}$ is noticeably increased from dry circuit measurements but might still appear to be relatively benign. However, when combined with the increased pressure os- 

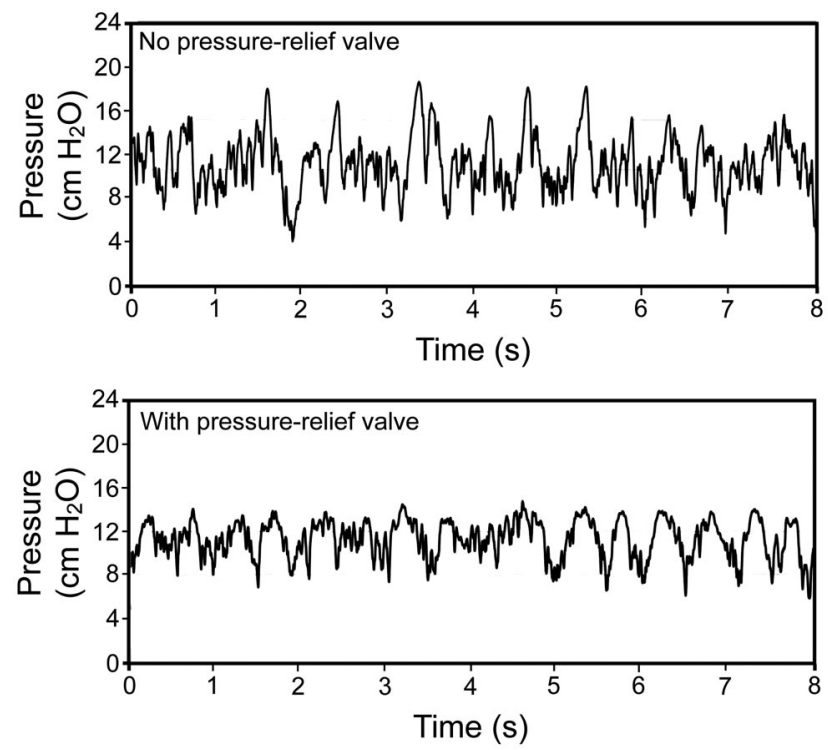

Fig. 7. Pressure waveforms with and without a pressure-relief valve in the circuit. The pressure signals were sampled at $1,024 \mathrm{kHz}$ for $8 \mathrm{~s}$, the CPAP depth was $5 \mathrm{~cm} \mathrm{H}_{2} \mathrm{O}$, the flow was $10 \mathrm{~L} / \mathrm{min}$, and the condensate volume was $20 \mathrm{~mL}$.

cillations, it is evident that the peak pressures reaching the infant are cause for concern. For example, at a flow of $6 \mathrm{~L} / \mathrm{min}$ a dry circuit delivers a peak pressure of $7.5 \mathrm{~cm} \mathrm{H}_{2} \mathrm{O}$ (mean $\mathrm{P}_{\text {tracheal }} 4.9 \mathrm{~cm} \mathrm{H}_{2} \mathrm{O}, \Delta \mathrm{P}_{\text {tracheal }} 2.6 \mathrm{~cm} \mathrm{H}_{2} \mathrm{O}$ ) while a wet circuit containing $10 \mathrm{~mL}$ of condensate delivers a peak pressure of $10.4 \mathrm{~cm} \mathrm{H}_{2} \mathrm{O}$ (mean $\mathrm{P}_{\text {tracheal }} 5.8 \mathrm{~cm} \mathrm{H}_{2} \mathrm{O}$, $\Delta \mathrm{P}_{\text {tracheal }} 4.6 \mathrm{~cm} \mathrm{H}_{2} \mathrm{O}$ ), which is twice the set CPAP level. Taking into account our measured rate of fluid accumulation of $3.8 \mathrm{~mL} / \mathrm{h}$, and using $10 \mathrm{~mL}$ as an arbitrary marker for the onset of unwarranted pressure spikes, an unattended bubble CPAP system in conditions similar to our experimental setup can reach potentially unsafe pressures $\left(>12 \mathrm{~cm} \mathrm{H}_{2} \mathrm{O}\right)$ in $<3$ hours.

Allowing delivered pressures to reach pressures significantly higher than those intended can result in serious physical consequences such as air leaks, overdistention, and gastric distention. ${ }^{13}$ Physiological consequences may include increased $\mathrm{P}_{\mathrm{aCO}}$, reduction in venous return, and compromised cardiac output. ${ }^{14,15}$

The additional resistive loading of the infant respiratory system from excessive fluid accumulation in the bubble CPAP circuit could potentially add to respiratory failure, by superimposing large airway pressure oscillations that are out of phase with the patient's intrinsic respiratory efforts. Imposed resistance through any or all of the airways during exhalation can produce alveolar hyperinflation, uneven regional ventilation, and excessive respiratory muscle loading, leading to increased work of breathing, impaired gas exchange, ${ }^{16}$ and failure to wean. ${ }^{17-22}$

As expected, the pressure-relief valve had an appreciable effect on the magnitude and frequency of the $\Delta \mathrm{P}_{\text {tracheal }}$ (see Figs. 6 and 7) but did little to decrease mean $\mathrm{P}_{\text {tracheal }}$ (see Fig. 5) to a level considered safe for some preterm neonates. Thus, an adjustable pressure-relief valve may provide better control over excessive pressure from condensate. Further, high-pressure audio alarms may be useful in warning clinicians of rising pressure.

Our suggestion that circuits be emptied every $2-3$ hours, to avoid potentially unsafe pressure, is based on our accumulation rate and pressure data, which have inherent limitations. We conducted the accumulation rate study at a single flow $(6 \mathrm{~L} / \mathrm{min})$; it may be reasonable to suspect that higher flows will result in greater fluid accumulation rates, due to the increased volume of humidified air flowing through the circuit. The test lung, though heated to $37^{\circ} \mathrm{C}$ and programmed to simulate breaths, cannot predict how the physiology of an infant's lung contributes to condensate formation in the expiratory circuit. However, since the exhaled gas is at body temperature and is saturated, it is likely that the infant will add moisture to the air, in which case our results may somewhat underestimate the actual rate of condensate formation. By having a completely airtight system, our measurements may overestimate the pressure that an infant actually receives. Small leaks around the prongs or at the mouth are commonplace in the neonatal ICU, especially if chin straps or pacifiers are not being used. Additionally, if a chinstrap is not in place, the mouth may serve as a natural pressure-relief valve should an obstruction in the circuit cause pressure to drastically increase.

Substitutions for or alterations in the proprietary nonheated exhalation circuit used with the Fisher \& Paykel bubble CPAP system may decrease the rate of condensate accumulation. An exhalation circuit with a heated wire may allow water to remain in vapor form; the extent to which a heated expiratory circuit affects condensate formation is an area for further study. Fisher \& Paykel's novel Evaqua 2 circuit allows water vapor to diffuse out of the tubing wall, which drastically decreases the amount of fluid condensate and circuit maintenance required. However, the added expense of the Evaqua 2 may make it inaccessible to many clinicians, particularly those in resource limited settings. Water traps have also been integrated into exhalation circuits to catch condensate and keep the circuit clear, but they are not well suited for use with bubble CPAP because the volume they add to the circuit may increase overall compliance and dampen the pressure oscillations that are both characteristic of, and desirable in, bubble CPAP.

\section{Conclusions}

Accumulated condensate in the expiratory limb of a bubble CPAP circuit increases the delivered pressure. We recommend that the operators of basic (ie, commercial 
systems without specialized circuits) or home-made bubble CPAP systems monitor pressure at the nasal airway interface to ensure that the pressure delivered to the infant matches the intended pressure. We encourage frequent emptying of condensate from the circuit, verification of proper heated humidifier settings, and the use of a pressure-relief valve set to $5 \mathrm{~cm} \mathrm{H}_{2} \mathrm{O}$ above the desired mean pressure.

\section{REFERENCES}

1. Gupta S, Sinha SK, Tin W, Donn SM. A randomized controlled trial of post-extubation bubble continuous positive airway pressure versus Infant Flow Driver continuous positive airway pressure in preterm infants with respiratory distress syndrome. J Pediatr 2009;154(5): 645-650.

2. Narendran V, Donovan EF, Hoath SB, Akinbi HT, Steichen JJ, Jobe AH. Early bubble CPAP and outcomes in ELBW preterm infants. J Perinatol 2003;23(3):195-199.

3. Aly H, Milner JD, Patel K, El-Mohandes AA. Does the experience with the use of nasal continuous positive airway pressure improve over time in extremely low birth weight infants? Pediatrics 2004; 114(3):697-702

4. Lee KS, Dunn MS, Fenwick M, Shennan AT. A comparison of underwater bubble continuous positive airway pressure with ventilator-derived continuous positive airway pressure in premature neonates ready for extubation. Biol Neonate 1998;73(2):69-75.

5. Nekvasil R, Kratky J, Penková Z, Stejskal J. [High frequency "bubble" oscillation ventilation in the neonatal period.]. Cesk Pediatr 1992;47(8):465-470. Article in Czech.

6. Kaur C, Sema A, Beri RS, Puliyel JM. A simple circuit to deliver bubbling CPAP. Indian Pediatr 2008;45(4):312-314.

7. Liptsen E, Aghai ZH, Pyon KH, Saslow JG, Nakhla T, Long J, et al. Work of breathing during nasal continuous positive airway pressure in preterm infants: a comparison of bubble vs variable-flow devices. J Perinatol 2005;25(7):453-458.

8. Kahn DJ, Courtney SE, Steele AM, Habib RH. Unpredictability of delivered bubble nasal continuous positive airway pressure: role of bias flow magnitude and nares-prong air leaks. Pediatr Res 2007; 62(3):343-347.

9. Kahn DJ, Habib RH, Courtney SE. Effects of flow amplitudes on intraprong pressures during bubble versus ventilator-generated nasal continuous positive airway pressure in premature infants. Pediatrics 2008;122(5):1009-1013

10. DiBlasi RM, Salyer JW, Zignego JC, Redding GJ, Richardson CP. The impact of imposed expiratory resistance in neonatal mechanical ventilation: a laboratory evaluation. Respir Care 2008;53(11):14501460.

11. Chan KM, Chan HB. The use of bubble CPAP in premature infants: local experience. HK J Paediatr (new series) 2007;12(2):86-92.

12. DiBlasi RM, Zignego JC, Tang DM, Hildebrandt J, Smith CV, Hansen TN, et al. Noninvasive respiratory support of juvenile rabbits by high-amplitude bubble continuous positive airway pressure. Pediatr Res 2010;67(6):624-629.

13. DiBlasi RM. Nasal continuous positive airway pressure (CPAP) for the respiratory care of the newborn infant. Respir Care 2009;54(9): 1209-1235.

14. Shaffer TH, Koen PA, Moskowitz GD, Ferguson JD, DelivoriaPapadopoulos M. Positive end expiratory pressure: effects on lung mechanics of premature lambs. Biol Neonate 1978;34(1-2):1-10.

15. Hobelmann CF Jr, Smith DE, Virgilio RW, Peters RM. Mechanics of ventilation with positive end-expiratory pressure. Ann Thorac Surg 1977;24(1):68-76.

16. Yoder BA, Martin H, McCurnin DC. Lung function measurements in a preterm animal model of respiratory failure: comparison of two different neonatal ventilators. Pediatr Pulmonol 2006;41(11):10691076 .

17. Banner MJ, Downs JB, Kirby RR, Smith RA, Boysen PG, Lampotang S. Effects of expiratory flow resistance on inspiratory work of breathing. Chest 1988;93(4):795-799.

18. Isono S, Nishino T, Sugimori K, Mizuguchi T. Respiratory effects of expiratory flow-resistive loading in conscious and anesthetized humans. Anesth Analg 1990;70(6):594-599.

19. Kirton OC, DeHaven CB, Morgan JP, Windsor J, Civetta JM. Elevated imposed work of breathing masquerading as ventilator weaning intolerance. Chest 1995;108(4):1021-1025.

20. Kirton OC, Banner MJ, Axelrad A, Drugas G. Detection of unsuspected imposed work of breathing: case reports. Crit Care Med 1993; 21(5):790-795.

21. Morganroth ML, Morganroth JL, Nett LM, Petty TL. Criteria for weaning from prolonged mechanical ventilation. Arch Intern Med 1984;144(5):1012-1016.

22. Dubois AB. Resistance to breathing. In: Fenn WO, Rahn H, editors. Handbook of physiology and respiration, volume 1. Washington, DC: American Physiology Society; 1964:451-462.

This article is approved for Continuing Respiratory Care Education credit. For information and to obtain your CRCE

(free to AARC members) visit www.rcjournal.com

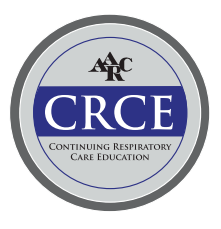

